\title{
Discussion on the Exit of Private Equity -A Case Study of IPO
}

\author{
Xiu-e Yuan, Dan Zhao, Chen-li Wang \\ North China Electric Power University(Baoding), Department of Economics and Management, Hebei Province, China
}

\begin{abstract}
Private Equity (Private Equity, abbreviated as PE) is to adapt to the market economy, facing numerous opportunities for investment opportunities, making up for the limitations of the traditional financing channels in terms of the scale of financing to meet the needs of enterprise development, and gradually developed as a mode of investment and financing from the financial market. This article will talk about my several immature ideas according to private equity investment.
\end{abstract}

Index Terms - private equity, IPO policy

\section{Introduction}

At this stage, with the rapid development of China's economy, the depth and breadth of investment may expand, the number and size of companies have taken advantage of the continuous development, faced with such developments, the traditional financing companies both in the breadth and depth of financing will be subject to certain restrictions, in such opportunities, private equity investments gradually assume an increasingly important role in the development of market economy . Here we simply learn about the concepts of private equity investment:

\section{A. Private Equity-Related Concepts}

Private equity (PE) refers to equity investments to nonlisted companies through the private equity fund. During the course of transaction, PE comes to consider the future exit mechanism, namely through the company's initial public offering (IPO), mergers and acquisitions (M\&A) or management buy-outs (MBO) and other ways to exit a profit. Simply speaking, PE is the PE investors looking for good fastgrowing unlisted firms, capital injection, get a certain percentage of its shares, and promote the company's development, then profit form the transfer of ownership.

1) General Private Equity: It points to specific investors to raise funds in private for non-listed companies, including in the seed, start-up stage, expansion, maturity or Pre-IPO of enterprise for equity investment, and then through a variety of methods making the invested enterprise to develop and realize the equity of value-added and consider the future of the special exit mechanism during the course of transaction, eventually profit form selling the holding shares.

2) Narrow Private Equity: It points to specific investors to raise funds in private on the already formed a certain scale and generate stable cash flow to develop and mature business investment, and to consider the future of the special exit mechanism during the course of transaction, eventually profit form selling the holding shares.
We based on general private equity investment as a background for discussion.

\section{B. Main Types of Private Equity}

Under the broad definition of private equity investment, from the investment stage, private equity investments are mainly divided into the following four types:

1) Venture Capital: Mainly invested in the start-up or early stage of industrialization, to fund its research and development and working capital.

2) Growth Fund: Investment in the industry after the success of the expansion phase, to provide enterprises with the necessary investment in fixed assets and working capital, to expand production and improve productivity.

3) Mergers and Acquisitions Fund: Through the acquisition of controlling mature and stable growth of enterprises, carry out internal restructuring, industry consolidation, etc. to help companies establish market position, enhance its intrinsic value, waiting for value-added sales profit.

4) Mezzanine Capital or Bridge Financing: Investing the enterprises which are stable growth before listed in the form of convertible bonds. Most of the private equity in the Pre-IPO stage belong to this type.

\section{Characteristics of Private Equity}

Private equity has its own characteristics, such as profittaking, the rate of return requirements. Characteristics of private equity investments can be summarized as follows:

1) Equity investment in non-listed company, due to poor liquidity, is considered as long-term investment, so investors will demand returns higher than the open market;

2) There is no ready market for transfer of stakes in nonlisted companies to deal directly with the buyer. While investors, holding money needs to be invested, and companies that need to be invested must rely on personal relationships, trade associations or other agencies to look for each other;

3) The sources of funds are wide, such as wealthy individuals, venture capital, leveraged buy-out funds, strategic investors, pension funds, insurance companies and so on;

4) There are three main ways of returning on investment: public offering, sale or merger, reorganization of the company's capital structure.

\section{Private Equity Operations}

Operational processes of private equity investments generally is collecting information on all aspects of the acquisition of the project, especially profit, market information 
or other data, then analyze on the collected information for each project, then through the present data, including macroeconomic analysis, industry analysis, the analyst research, financial analysis, product analysis, market analysis, etc., and ultimately predict future stock prices, profitability level, etc. , combine with capital investment plans and capital exit ways to calculate ROI, and then decide whether to invest.

\section{E. Private Equity Exit Mechanism}

Private equity exit mechanism mainly includes IPO (Initial Public Offering), acquisition, buyback, secondary sale and write off. Integrated foreign private equity investing in well-developed countries, since with a sound legal system, the higher degree of equity market capitalization and other favorable factors, IPO became the highest return on investment of the exit ways, and then developed into the main exit way. If the IPO is not possible, then the MBO will be used more.

\section{Current Chinese IPO Policy's Impact on Private Equity}

When it comes to the current Chinese IPO policy's impact on private equity investment, it is not difficult to find at this stage our IPO is the main exit route for private equity, so talk about the development of China's private equity market and the impact of China's current policy IPO, we have to discuss the following questions clearly:

\section{A. Current Situation of Chinese Private Equity}

In recent years, by the development of international private equity markets and the rapid growth of China's economy, China's private equity's development is fairly rapid. In general, the development of China's private equity investment has the following four characteristics:

1) Foreign Private Equity are Active in China's Private Equity Market.

Foreign private equity investments with its own maturity are active in china, whose economy develops rapidly in recent years, at a rate of about 8 percent annual growth, there are many opportunities to invest, start-ups companies increase quickly, while traditional financing is limited to the financing conditions, China's domestic private equity is temporarily in the immature stage, foreign private equity investment has found a big development space for himself.

2) All Kinds of Financial Institutions have Started to Get Involved in Private Equity Markets.

Trust companies, securities companies, qualifying insurance companies, the National Development Bank, which seemed as administrator or as fund holder, are entering into the domestic private equity market.

3) The Active Participation of Local Governments, the Enthusiasm in the Private Equity Market has been Mobilized.

In January 2007, after the special approval by the State Council, the management company of Bohai industrial investment fund, which invest mainly in Tianjin Binhai and Bohai Rim, was established. Bohai Industrial Investment Fund was totally 20 billion yuan, raising 6.08 billion yuan for the first time. In May, Guangdong, Shanxi, Shanghai, Sichuan and other four industry funds has became the second batch of pilot of national development and reform commission industrial fund.

4) IPO is the Main Exit Way for Private Equity in China, the Government is Actively Guiding the Private Equity to Come to the Market.

Summary analysis: it is undoubtedly more and more important in China's private equity to participate in the fierce competition of foreign private equity fund, conforming to the trend of private equity market when faced with government and major financial institutions that have set foot in the private equity, but the core competencies in the competition is the ROI of various private equity funds.

\section{B. Overview of China's Current Policy IPO}

Throughout the development of China's IPO policies, and with the chairman of the SFC transition, the recent IPO policies are very intensive. We have found that the current IPO is more regulated than before, such as registration system. Through the knowledge of the IPO, we will analyze on several outstanding policies as follows, in order to understand the current IPO intuitive policy more comprehensively.

\section{1) Push the Reform of Registration System}

This reform is an important step to advance equity issuance from an approval system to a registration system.IPO reform does not mean deregulation, while improving the preaudit, at the same time, enhancing monitoring, exacting law enforcement afterwards. For issuers, major shareholders, intermediaries, etc., once illegal trail, stop auditing timely, transferred to the judicial and other measures to strengthen accountability, increase penalties, and earnestly safeguard the market to be openness, fairness and justice.

2) For the IPO, "Three High", "Money" Issue

After the reform, it will no longer perform "25 percent rule." Promoting the old shareholders to transfer their stock and increasing the supply of new shares.

When determining the issue price, firstly remove the top $10 \%$ of the purchase amount of the quotation. The highest quotation can't affect the issue price and the highest bidder can't obtain the allotment, in order to prevent the "human quotation" or blind to high prices.

3) Placing the Lead Underwriter for Introducing Independent Mechanism

Underwriter can place stock, which issued under the net according to principle of prior announcement, to their customers. Lead underwriters, for long-term clients, need to set a reasonable price to balance the interests of buyers. This will help prevent the underwriter and issuer seeking high prices.

4) Participation in Online Placements of Investors Holding Non-restricted Equity

Holding a certain number of non-restricted shares of investors can participate in online purchase, online placement should consider the market value of investors' holding nonrestricted equity and the amount of purchasing, then numbering and balloting. 


\section{5) Releasing the Old Stock Transfer Measures}

When starting, it allow shareholders to offer the shares of stock to the public.

Intends transfer of old shares need hold more than 36 months in order to prevent the fast cash; when transferred, the equity structure of the company shall not be changed significantly, the actual control can't be changed, preventing the instability;

The company should first determine the total number of public offerings and old stock transfer number, new shares issued number based on inquiry situation and the demand of project fund, which can curb the ultra-raised funds and contribute to stable investors' expect as well as reasonable quotes.

\section{IPO Impact of New Requirements on Listing Companies}

Background: The history of pre-disclosure is refreshed, but with the same time the review process that has been carried many years is transformed. April 18, 2014 afternoon, the Commission announced a new episode review process, involving changes in three aspects. First, the Ministry of Supervision, after the formal acceptance, should arrange predisclosure according to the procedure, feedback responses prior to the trial, then arrange the pre-disclosed updates. Second, given that requesting to set up internal nuclear mechanism, it will no longer set up asking procedure during the review process. Third, the first meeting will be held after the feedback session.

At 23:30 on April 182014 or so, the Commission issued its first list of pre-disclosure, closing at 0:35 on the 19th, a total of 28 listed companies announced the IPO prospectus. Since the October 25, 2012, this is the first time the company to disclose, which means that the window of IPO restart is open. In the first pre-disclosure list, 16 companies to be listed on the Shanghai Stock Exchange main board, 4 companies to be listed on the Shenzhen Stock Exchange's junior, 8 companies to be listed on the GEM.

Background analysis: behind of this adjustment is the process reengineering. In the first part, it's equal to established the new iterations of the pre-disclosure, ensuring that the information is updated in real time, and left marks, reflecting the new reform ideas. Corresponds to the issuer and sponsor's changes, this will greatly change the past---"squeezing toothpaste" type of information disclosure practices.

In the second part, the original arrangement aims to urge, to remind the sponsor and representatives doing good job of due diligence, participants including auditors in audit division I and II, two signature representative of the sponsor and sponsor-related in charge.

In the third part, it is for efficiency enhancement. The original meeting was aiming to establish a preliminary communication mechanism between issuers and the ministry of supervision. Meeting attendees include representatives of issuers, the supervision heads, general office, head of the audit office and the audit division. The issuer will simply introduce the enterprise's basic situation in the meeting. The supervision head introduce the issue procedures, standards, concepts and disciplinary requirements.

Original feedback meeting, checked applying document by auditors in audit division I and II, wrote audit reports from the point of non-financial and financial and submitted feedback meeting discussion. Feedback meeting mainly discuss the main concerned issue in the preliminary check, determining the question of additional disclosure, further explanation and verification of implementation. It will form written comments after feedback meeting, perform internal procedure, then feed back to sponsors. When sponsors have received the feedback, issuers and related organizations should implement and reply in accordance with the requirements. Auditors check the application document and reply data according to the requirement.

In fact, on this original program schedule, due to the lack of pre-targeted communication, making the appointment of more auditors a brief introduction process, after going through an adjustment, making the appointment can be performed on targeted basis, communication efficiency is naturally enhanced. En the original process, the GEM review on the implementation of the program in accordance with this.

\section{3. .Summary}

\section{A. Recommendations of Exit Choice}

About private equity exit mode selection, in conjunction with the determination of the characteristics of investments, private equity exits directly determine the specificity of the equity investment.

\section{B. Recommendation of IPO Policy}

Most investors believe that a new round of IPO reformation for the market is still bearish, and hold that the behavior of curbing hype is useless, in the final analysis our stock market development can't keep up with the economic development. Stock market will not become a speculative game sites, while attracting more funds into the market, become channels for investment, providing financial support for economic development. This requires that solve the fundamental problem and promote healthy development of the stock market.

\section{Conclusion}

Private equity has important meaning for a country's economic development and contributes to enterprise's growth development, so it should greatly guide, support, develop private equity. In a round of private equity process, value assessment undoubtedly is an important part to invested enterprise, accurate of value assessment is adapted to market development and government direct, and finally achieve stable and more objective accurate of private equity income, coordination interests of all parties to reach a fair, win-win situation.

\section{References}

[1] Jinhua, "private equity fund", Xiang Yang University Press, May 2011.

[2] Sun Ru, "Private Equity Research for SMEs", March 2011.

[3] Pan Qilong, "Private Equity practice and case", Economic Science Press, January 2011, 2nd Edition. 